\title{
Photochemistry Aspects of the Laser Pyrolysis Addressing the Preparation of Oxide Semiconductor Photocatalysts
}

\author{
R. Alexandrescu, ${ }^{1}$ I. Morjan, ${ }^{1}$ F. Dumitrache, ${ }^{1}$ M. Scarisoreanu, ${ }^{1}$ I. Soare, ${ }^{1}$ C. Fleaca, ${ }^{1}$ R. Birjega, ${ }^{1}$ \\ E. Popovici, ${ }^{1}$ L. Gavrila, ${ }^{1}$ G. Prodan, ${ }^{2}$ V. Ciupina, ${ }^{2}$ G. Filoti, ${ }^{3}$ V. Kuncser, ${ }^{3}$ and L. Vekas $^{4}$ \\ ${ }^{1}$ National Institute for Lasers, Plasma and Radiation Physics, P.O. Box MG 36, 077125 Bucharest, Romania \\ ${ }^{2}$ Ovidius University of Constanta, P.O. Box 8600, 900527 Constanta, Romania \\ ${ }^{3}$ National Institute of Materials Physics, P.O. Box MG 7, 077125 Bucharest, Romania \\ ${ }^{4}$ Centre for Fundamental and Advanced Technical Research, Romanian Academy, Timisoara Branch, \\ Bd. Mihai Viteazul 24 RO, 300223 Timisoara, Romania
}

Correspondence should be addressed to R. Alexandrescu, ralexandrescu2001@yahoo.co.uk

Received 28 April 2008; Accepted 25 June 2008

Recommended by Mohamed Sabry Abdel-Mottaleb

The laser pyrolysis is a powerful and a versatile tool for the gas-phase synthesis of nanoparticles. In this paper, some fundamental and applicative characteristics of this technique are outlined and recent results obtained in the preparation of gamma iron oxide $\left(\gamma-\mathrm{Fe}_{2} \mathrm{O}_{3}\right)$ and titania $\left(\mathrm{TiO}_{2}\right)$ semiconductor nanostructures are illustrated. Nanosized iron oxide particles $(4$ to $9 \mathrm{~nm}$ diameter values) have been directly synthesized by the laser-induced pyrolysis of a mixture containing iron pentacarbonyl/air (as oxidizer)/ethylene (as sensitizer). Temperature-dependent Mossbauer spectroscopy shows that mainly maghemite is present in the sample obtained at higher laser power. The use of selected $\mathrm{Fe}_{2} \mathrm{O}_{3}$ samples for the preparation of water-dispersed magnetic nanofluids is also discussed. $\mathrm{TiO}_{2}$ nanoparticles comprising a mixture of anatase and rutile phases were synthesized via the laser pyrolysis of $\mathrm{TiCl}_{4}$ - (vapors) based gas-phase mixtures. High precursor concentration of the oxidizer was found to favor the prevalent anatase phase (about 90\%) in the titania nanopowders.

Copyright (c) 2008 R. Alexandrescu et al. This is an open access article distributed under the Creative Commons Attribution License, which permits unrestricted use, distribution, and reproduction in any medium, provided the original work is properly cited.

\section{INTRODUCTION}

In recent years, research interests for the preparation and application of oxide semiconductor photocatalysts have continuously grown [1]. Particular attention is paid to the use of semiconductor materials as photocatalysts for the removal of organic and inorganic species from aqueous or gas phase. This method has been suggested in environmental protection due to its ability to oxidize the organic and inorganic substrates [2]. Several steps should characterize the heterogeneous photocatalysis reaction among which most important should be the adsorption and the reaction onto the surface [3].

Studies were made on compositions consisting mainly of various oxide semiconductors. For instance, commonly used $\mathrm{Fe}_{2} \mathrm{O}_{3}$ semiconductor oxide is known for its catalytic activity $[4,5] . \mathrm{TiO}_{2}$ nanoparticles offer additional advantages (low cost, chemical inertness, highly photo-activity, and suitable band gap $(\mathrm{Eg}=3.2 \mathrm{eV}))[6-8]$.

The photocatalytic activity of a particulate semiconductor system depends on the crystal structure, crystallinity, particle size and shape, size distribution, surface area, and surface hydroxyls. Considerable enhancement of the absorption can be observed in small nanocrystals, where the surface-to-volume ratio is very high and the share of the surface atoms is sufficiently large. Consequently, the synthesis method plays a fundamental role.

A wide variety of gas-phase techniques has been developed for the fabrication of nanoparticulate structures [9] which could allow for homogeneous nucleation and may provide to some extent the control of particle size, particle shape, size distribution, particle composition, and degree of particle agglomeration. Among these synthesis procedures, the laser pyrolysis technique has been developed recently as 
a powerful tool for the synthesis of technological important nanomaterials such as metallic $(\mathrm{Fe}, \mathrm{Ti})$ oxides and composites [10-13], silicon crystals [14], nanocarbon [15], and ironsiloxane polymer nanoparticles [16].

This paper represents an extension of our earlier analysis on the principles of the laser pyrolysis and its applications [17]. Here, we shortly discuss the background of the method and recent development in the field, with special emphasis on the preparation of two types of semiconductor photocatalysts: maghemite iron oxide and titanium dioxide. In Section 2, the pyrolysis of $\mathrm{Fe}(\mathrm{CO})_{5}$-based gas mixtures and the preparation of magnetic nanofluids are presented in a sequence relevant for the phenomenology of the process and the nanopowder structure. In Section 4, main characteristics of the laser-sensitized pyrolysis of $\mathrm{TiCl}_{4}$-based mixtures for producing titania and anatase titania in connection with their specific structural characteristics are discussed.

\section{LASER PYROLYSIS SYNTHESIS}

\subsection{Photochemical aspects of the laser pyrolysis}

The specific features of the $\mathrm{CO}_{2}$ laser pyrolysis rely on the IR vibrational photochemistry. The process is based on the overlapping of the emission line of the laser (the strong 10P (20) line that peaks at $10.591 \mu \mathrm{m}$ ) with an absorption line of one or more gas precursors [17]. The molecular mechanism involves the increase of the internal energy of the ground electronic state, the evolution of the vibrational states through collisional relaxation processes, and finally the thermochemical reactions. Flynn et al. [18] show that in any environment where multiple collisions occur on the time scale of a chemical reaction, the vibrational modes of a polyatomic molecule will equilibrate, and reaction occurs without energy localization in a single mode. An additional substance, the so-called sensitizer is used in case of nonabsorbing gas precursors. It will absorb the energy and transmit it to the precursors by collisions. This energy transfer agent plays a high practical role (detailed for ethylene in what follows) because it assures the coupling between the laser radiation and the absorbing system. As a final effect of the coupling between the laser radiation and the absorbing system, the laser acts as a localized heat source. As compared to heating the gases in a furnace, the laser heating is a localized one occurring only in a small volume delimitated by the radiation cross section and the emergent gas flows. Short millisecond-scale residence times, spatial uniformity of the reaction zone, and continuous source of activation energy are the key attributes of the process.

$\mathrm{Fe}(\mathrm{CO})_{5}$ and $\mathrm{TiCl}_{4}$ are greatly used as precursors in conventional CVD or in photolytic or thermally laserinduced processes [19]. $\mathrm{Fe}(\mathrm{CO})_{5}$ and $\mathrm{TiCl}_{4}$ molecules meet also other prerequisites for CVD, like stability and relevant vapor pressure at room temperature (around 25 torr and 8 torr at $300 \mathrm{~K}$, resp.). The IR spectra of both of $\mathrm{Fe}(\mathrm{CO})_{5}$ and $\mathrm{TiCl}_{4}$ present no absorption bands near the emission frequencies of the $\mathrm{CO}_{2}$ laser.

In the sensitized $\mathrm{CO}_{2}$ laser pyrolysis of $\mathrm{Fe}(\mathrm{CO})_{5} / \mathrm{TiCl}_{4}$, the IR radiation is used to resonantly excite $\mathrm{C}_{2} \mathrm{H}_{4}$ sensitizer.
The absorption coefficient of $\mathrm{C}_{2} \mathrm{H}_{4}$ at the laser radiation wavelength of the usual $\mathrm{CO}_{2}$ lasers is $1.7 \times 10^{-3} \operatorname{torr}^{-1} \mathrm{~cm}^{-1}$. Ethylene is excited in a superposition of two fundamentals: $\nu_{7}$ $\left(949.3 \mathrm{~cm}^{-1}\right)$ and $\nu_{8}\left(940.6 \mathrm{~cm}^{-1}\right)$. The dissociation energy $\mathrm{H}_{2} \mathrm{C}-\mathrm{CH}-\mathrm{H}$ (for one hydrogen stripping) is rather high (103 Kcal/mol [20]).

Ideally, it is supposed that ethylene only transfers its energy by collisions to the other precursors, but do not participate in the reaction. However, the study of the evolution of the exhaust gases often shows that at higher temperatures ethylene could also decompose. Indeed, as a first product of decomposition, acetylene is released and appears as traces in the IR spectrum of the exhaust gases. One should note that the observed $\mathrm{C}_{2} \mathrm{H}_{4}$ dehydrogenation could be significantly promoted by the active $\mathrm{Fe}$ sites generated by $\mathrm{Fe}(\mathrm{CO})_{5}$ dissociation. As shown in [21], although the thermodynamically favored process is the iron pentacarbonyl dissociation, the hydrocarbon decomposition could be speeded up by the catalytic surface of freshly formed iron nanoparticles.

\subsection{Advantages and drawbacks}

The laser pyrolysis processes are characterized by high temperatures, fast heating rates, and short reaction times. These features make the laser pyrolysis attractive method for the manufacture of technological useful materials at lower costs compared to conventional gas-phase processes (such as the flame spray processes). Some other advantages are (i) the relative simple equipment, (ii) the versatility - the formation of virtually any nanoproducts, provided a suitable choice of precursors, and (iii) formation of high purity products.

The drawbacks of the laser pyrolysis technique are sometimes found in the constraints imposed on the precursors [6]: the desired elements must be present in vapor phase and at least one reactant should contain an infrared absorption band for the coupling of the energy with the laser beam.

\subsection{Experimental set-up}

The flow reactor is the core of the laser pyrolysis technique, ensuring the practical application of the characteristic interplay between resonant and nonresonant processes. It was presented in details elsewhere [17]. A schematic view of the setup is presented in Figure 1. Briefly, the system is based on a cross-flow configuration. The reactant flow emerges in the reactor through a nozzle system where it is orthogonally intersected by the focused IR radiation beam. Pyrolysis in the gas phase occurs in the small volume defined by the radiation-gases crossing where a "flame" usually appears. It is believed that the visible emission is mainly resulting from the hot freshly nucleated particles. The confinement of gas precursors and of the particles toward the flow axis is achieved by a coaxial argon flow. Nucleated particles are kept entrained by the gas stream and collected in a removable tank at the exit of the reaction cell. Main process parameters are the nature of the gas (vapor) precursors, gas flow rates, pressure, as well as laser wavelength and laser power. For 


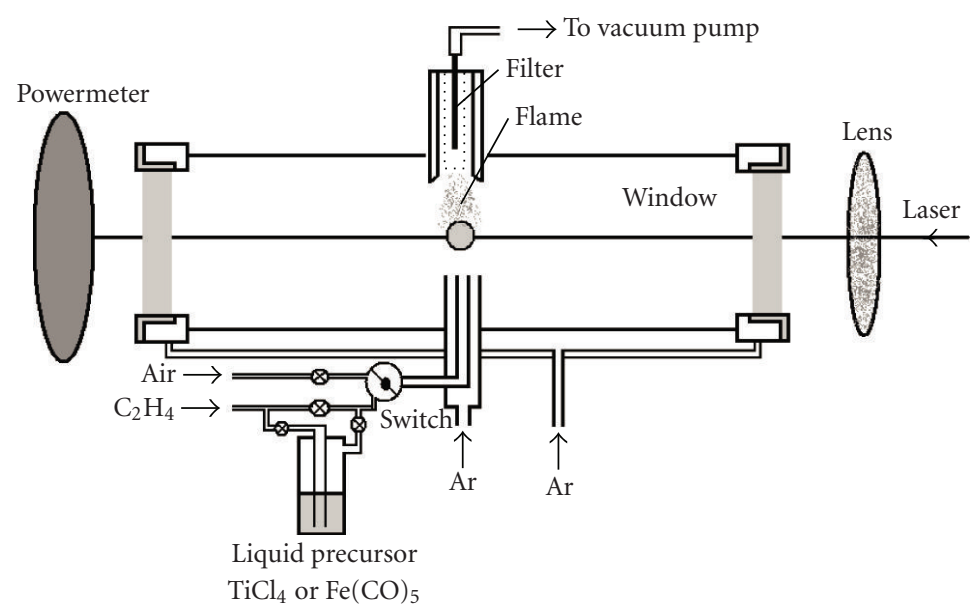

FIGURE 1: Schematic view of the laser pyrolysis setup for the production of iron oxide and titania nanoparticles, respectively.

liquid precursors, the bubbled vapors are entrained into the reaction zone by a carrier gas.

$\mathrm{Fe}(\mathrm{CO})_{5} / \mathrm{C}_{2} \mathrm{H}_{4}$ and $\mathrm{TiCl}_{4} / \mathrm{C}_{2} \mathrm{H}_{4}$ - were alternatively used as basic precursor mixtures for the preparation of iron and titanium oxide nanoparticles, respectively. In Figure 1, both these experimental arrangements are suggested. Additives such as air were employed for obtaining specific oxide nanostructures. In order to prevent the $\mathrm{NaCl}$ windows from being coated with powder, they were continuously flushed with Ar. Usually, either ethylene or argon was carrying through a bubbler the vapors of the liquid metal precursor into the reaction zone. In each of these systems, the installation for laser pyrolysis was adapted to the demands imposed by the nature of the precursors and the final aim of the synthesis process. In case of titania nanoparticles, a main variable trend was the change of a double nozzle system with a triple one (not shown in Figure 1) thus trying to avoid the direct reaction of $\mathrm{TiCl}_{4}$ with air.

\subsection{Material characterization}

After synthesis, the morphology and composition of the iron oxides nanopowders were characterized by transmission electron microscopy (TEM), selected area electron diffraction (SAED), X-ray diffraction (XRD), and Mössbauer spectroscopy. The XRD pattern was recorded on a DRON DART UM-2 diffractometer equipped with a $\mathrm{Cu} \mathrm{K}_{\alpha}$ radiation and a graphite monochromator in the diffracted beam. The crystallite sizes were calculated from the corrected full width and half maximum (FWHM) applying the Debye-Scherrer formula. The powdery deposits were imaged in a transmission electron microscope Philips CM120ST (Customized Microscope 120 Super Twin, $120 \mathrm{kV}$ max. acceleration voltage, about $2 \mathrm{~A}$ resolution, $\mathrm{Cs}=\sim 1.2 \mathrm{~mm}$ ). The samples were analyzed by the different electron microscopy techniques such as Bright Field Transmission Electron Microscopy (BFTEM), Selected Area Electron Diffraction (SAED) and High Resolution Transmission Electron Microscopy (HRTEM). ${ }^{57} \mathrm{Fe}$ Mössbauer spectroscopy was used for analyzing the samples at temperatures ranging from $80 \mathrm{~K}$ to $230 \mathrm{~K}$.
Mössbauer spectra were collected in transmission geometry by inserting the sample in a bath liquid-nitrogen cryostat. A Mössbauer drive system operating in constant acceleration mode combined with conventional electronics and a ${ }^{57} \mathrm{Co}$ (Rh matrix) source of about $25 \mathrm{mCi}$ activity were employed.

\section{RECENT EXAMPLES OF AND ADVANCES IN THE PREPARATION BY LASER PYROLYSIS OF OXIDE SEMICONDUCTOR PARTICLES}

\subsection{Spinel-like iron (III) oxide $\left(\gamma-\mathrm{Fe}_{2} \mathrm{O}_{3}\right)$}

\subsubsection{The preparation of the nanoparticles and of their magnetic fluids counterparts}

\section{Nanoparticle preparation}

For producing nanosized iron oxide particles, the focused continuous-wave $\mathrm{CO}_{2}$ laser radiation $(80 \mathrm{~W}$ maximum output power, $\lambda=10.6 \mu \mathrm{m}$ ) orthogonally crossed the gas flows emerging through two concentric nozzles (Figure 1). The gas mixture which contained air and $\mathrm{Fe}(\mathrm{CO})_{5}$ vapors (about 25 Torr vapor pressure at $20^{\circ} \mathrm{C}$ ), entrained by $\mathrm{C}_{2} \mathrm{H}_{4}$, was admitted through the central inner tube. Iron oxide samples (labeled as 01 and 02) were obtained by varying the laser power between $35 \mathrm{~W}$ and $55 \mathrm{~W}$ as presented in Table 1. The other experimental conditions, namely, the reactor pressure, the relative flow of the oxidizing agent (air), and the flow of ethylene (as $\mathrm{Fe}(\mathrm{CO})_{5}$ carrier) were maintained constant (their values are displayed in Table 1).

\section{Magnetic fluid preparation}

The as-synthesized iron oxide nanopowders were used for the preparation of magnetic nanofluids. In what follows, the obtained magnetic fluid samples will be labeled MF01 and MF02 and are derived by dispersing in water samples 01 and 02, respectively. Water-based magnetic nanofluids are a special category of polar magnetic nanofluids showing particularities as concerning particle interactions and agglomerates formation. The synthesis of magnetic 
TABLE 1: Experimental parameters and main crystallographic characteristics (estimated from XRD analysis) for the as-synthesized nano iron oxide samples.

\begin{tabular}{|c|c|c|c|c|c|c|c|c|c|}
\hline \multirow{2}{*}{ Sample } & \multirow{2}{*}{$\begin{array}{l}\Phi_{\mathrm{C}_{2} \mathrm{H}_{4}}{ }^{*} \\
\text { (through } \\
\mathrm{Fe}(\mathrm{CO})_{5} \\
{[\mathrm{sccm}]}\end{array}$} & \multirow{2}{*}{$\Phi_{\text {air }}{ }^{*}[\mathrm{sccm}]$} & \multirow{2}{*}{$P^{* *}[\mathrm{mbar}]$} & \multirow{2}{*}{$P_{L}^{*}[$ watt $]$} & \multicolumn{2}{|c|}{$\mathrm{XRD}$ analysis } & \multicolumn{3}{|c|}{ EDAX-elemental analysis, at $\%$} \\
\hline & & & & & $\begin{array}{l}a \text { (unit cell } \\
\text { parameter) ['] }\end{array}$ & $\begin{array}{l}D \text { (mean } \\
\text { crystallite } \\
\text { dimension })[\mathrm{nm}]\end{array}$ & $\mathrm{Fe}$ & $\mathrm{O}$ & $\mathrm{C}$ \\
\hline 01 & 145 & 70 & 300 & 55 & 8.364 & 4.5 & 36.29 & 52.99 & 10.72 \\
\hline 02 & 145 & 70 & 300 & 35 & 8.377 & 3.0 & 35.09 & 55.12 & 9.79 \\
\hline
\end{tabular}

${ }^{*} \Phi_{\mathrm{C}_{2} \mathrm{H}_{4}}$ and $\Phi_{\text {air }}$, are the flows of the ethylene (carrier of $\mathrm{Fe}(\mathrm{CO})_{5}$ vapors) and of air oxidizer, respectively (in standard cubic centimeter per minute);

** $P$ is the pressure in the reaction chamber (in mbar);

${ }^{* * *} P_{L}$ is the laser power (in Watt).

fluids has two main stages (1) preparation of nanosized magnetic particles, in particular by laser pyrolysis, and (2) subsequent stabilization/dispersion of the nanoparticles in water carrier. Electrostatic and steric stabilization procedures are both applicable for water-based magnetic nanofluids. Double layers steric + electrostatic (combined) stabilization of magnetic nanoparticles in water carrier was experimented recently using various chain length of carboxylic acid surfactants, as well as dodecyl benzensulphonic acid (DBS) [22]. In case of magnetic nanoparticles prepared by laser pyrolysis, a complementary difficulty appears due to the large agglomerates existing already in the nanopowder state, as a consequence of the magnetic dipolar interactions between uncoated nanoparticles. The sequence of steps of the preparation procedure for water-based magnetic nanofluids may be summarized as follows: (a) addition of $\mathrm{NaOH}(6 \mathrm{~N})$ to the water/magnetic nanopowder mixture in order to ensure a $\mathrm{pH}$ value of about 8.5-9, followed by heating up the reaction medium to about $75-80^{\circ} \mathrm{C}$; (b) chemisorption of the surfactant (in the present case, lauric acid (LA)); (c) magnetic organosol; (d) magnetic decantation (elimination of residual salts); (e) correction of $\mathrm{pH}$ (using $\mathrm{NaOH}$ ); (f) dispersion of surface-coated magnetic nanoparticles; (g) primary magnetic nanofluid; (h) magnetic decantation/filtration; (i) water-based magnetic nanofluid (diluted, with solid volume fraction of about 5\%).

\subsubsection{Nanoparticle characterization}

The XRD analysis of the as-synthesized nanopowders points to the presence of the spinel-like iron (III) oxide [10], namely, maghemite/magnetite iron phase (according to JCPDS 19-0629 for standard maghemite and JCPDS 39-1346 for maghemite). In Figure 2, a representative diffractogram obtained for the as-synthesized oxides is displayed. Although it refers to sample 01, its characteristic phase identification features are similar to that of sample 02 (not presented here). The unit-cell parameter (Table 1) was estimated from the 311 and 440 reflections. It presents relatively lower values to the standard magnetite value $\left(\mathrm{Fe}_{3} \mathrm{O}_{4}\right.$ with $\left.a=8.396 \AA\right)$, suggesting the formation of a more likely maghemite phase $\left(\gamma-\mathrm{Fe}_{2} \mathrm{O}_{3}\right)$. The broadness of the diffraction lines is associated with the formation of very small particles as well as with a high degree of structural/crystallographic disorder. The estimated mean crystallite dimension $\mathrm{D}(\mathrm{nm})$ is presented

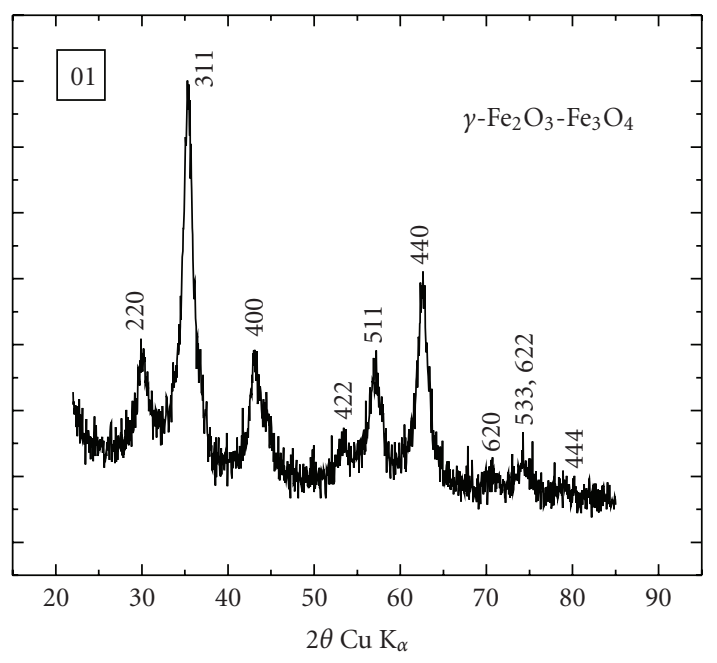

FIGURE 2: XRD diffraction patterns for a laser-synthesized iron oxide (sample 01): peak identification points to a chemical composition containing maghemite/magnetite iron oxide phases.

in Table 1. A higher crystallinity and slightly larger mean crystallite size may be deduced for the sample obtained at the higher laser power.

The identification of elements present in powders was performed using the energy dispersive analysis by X-rays (EDAX). The results are presented in the last column of Table 1. The stoichiometry, suggested by the relative quantities of oxygen and iron present in the synthesized powders, corresponds to a $\mathrm{Fe}^{3+}$ iron oxide, most probably maghemite. A rather low carbon contamination (about $10 \%$ ), mainly due to the unwanted ethylene dissociation may be noticed. Although revealed by EDAX, the XRD analysis seems not able to reveal traces of carbon. It is worth to note that the sensitivity of this analysis is down to a few atomic percent and that low $\mathrm{Z}$ elements are detectable with limited sensitivity.

TEM analysis of samples 01 and 02 reveals an almost polycrystalline morphology (Figures $3(\mathrm{a}), 3(\mathrm{~b})$ ). The nanoparticles show coalescent features. Cross-linked chains may be sometimes observed. An estimation of the particle mean sizes gives about 4.5 and $6 \mathrm{~nm}$ for samples 01 and 02 , respectively. 


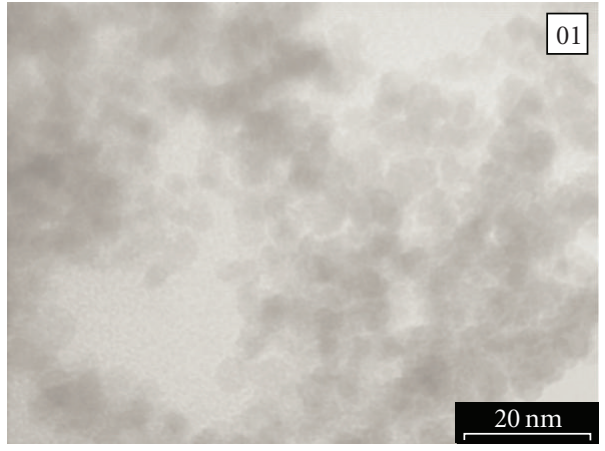

(a)

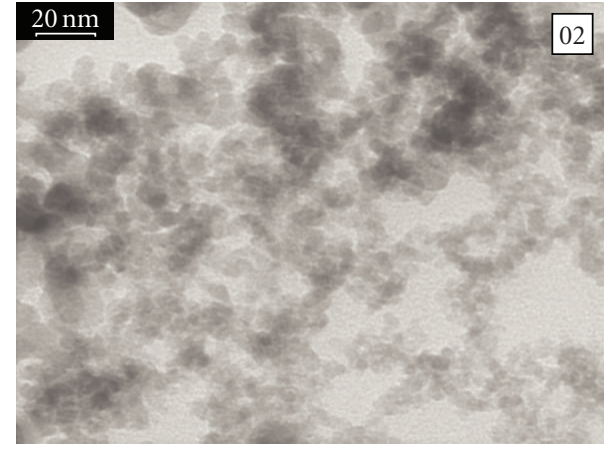

(b)

FIGURE 3: TEM analysis for iron oxides obtained from (a) sample 01 and (b) sample 02.

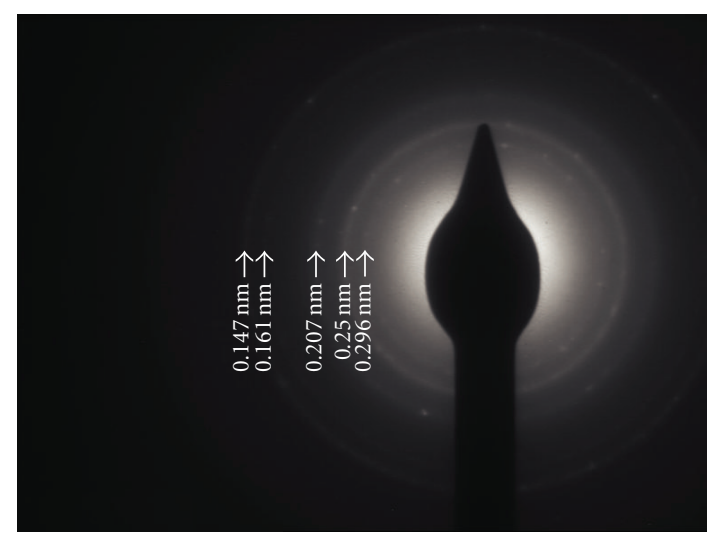

FIGURE 4: SAED analysis of sample 02 , revealing main diffraction rings of maghemite/magnetite.

The reflections revealed by the SAED analysis (Figure 4) may be attributed to a cubic structure of the iron oxide, namely, maghemite/magnetite. The strong diffraction ring at $0.25 \mathrm{~nm}$ may be noticed. Although difficult to distinguish between these phases from electron diffraction patterns alone, it is probable that maghemite prevails by referring to XRD results (see, e.g., the value of the estimated lattice parameter $a$ in Table 1 ). Increased crystallinity seems to characterize the nanomaterial obtained at higher laser power. This can be considered as a consequence of both the higher temperature gradients in the reactions zone and the fast quenching of the condensed nanoparticles in the condensation zone. As revealed by the characterization methods employed, this process greatly favors maghemite phase in powders.

HRTEM analysis was performed on many different domains of the nanopowders and is presented in Figure 5. Nanocrystals with different orientation and mean diameters of about $5-6 \mathrm{~nm}$ are displayed in Figure 5(a). From the indicated squarish areas, the Fourier transform images are presented as insets. The left-side and the right-side groups of nanocrystals in Figure 5(a) display characteristics of the cubic structure of a maghemite crystal. The lattice fringes, corresponding to the $(113)\left(d_{113}=0.253 \mathrm{~nm}\right)$ and to the $(220)\left(d_{220}=0.313 \mathrm{~nm}\right)$ planes, are evidenced. A small distribution of $d$-values is caused by the imperfect crystallographic structure, probably due to the quenching of the material when leaving the reaction zone. The HRTEM image of Figure 5(b) presents agglomerated nanocrystals. They seem to be surrounded by an amorphous layer.

\subsubsection{Magnetic properties for the as-synthesized particles and for the processed magnetic nanofluids}

The magnetic properties of the samples were studied by temperature-dependent Mössbauer spectroscopy. The $80 \mathrm{~K}$ Mössbauer spectra of the analyzed samples are shown in Figure 5. The derived probability distributions of the hyperfine field are presented at the right side. The narrow peak of the distribution, centered at about $52 \mathrm{~T}$, evidences the presence of mainly maghemite in sample 01 . The larger distribution peak centered at about $48 \mathrm{~T}$ in sample 02 might have two different reasons: (i) a starting magnetic relaxation process already present at $80 \mathrm{~K}$ and (ii) a much defected structure shifting structurally from maghemite to magnetite (the average magnetic hyperfine field of magnetite being lower than the one of maghemite). The magnetic relaxation process was analyzed [23] in terms of the collapsing behavior of the Mössbauer spectra at higher temperatures. From the Mossbauer spectra obtained at different temperatures, blocking temperatures of about $400 \mathrm{~K}$ and $200 \mathrm{~K}$ were derived for samples 01 and 02, respectively. Particle average sizes of about $9 \mathrm{~nm}$ for sample 01 and, respectively, $7 \mathrm{~nm}$ for samples 02 were estimated, starting from the abovementioned blocking temperatures and considering noninteracting nanoparticles.

The ferrofluids obtained by dispersing the nanopowders in water showed blocking temperatures of $230 \mathrm{~K}$ and $200 \mathrm{~K}$ for samples MF01 and MF02, respectively. It is worth mentioning that the higher blocking temperature observed for 01 as compared to MF01 is most probably generated by nonnegligible interparticle interactions in the powder sample (e.g., the substantial presence of maghemite with its ferri-magnetic behavior). In the defected maghemitemagnetite mixtures (sample 02), a spin-glass-like structure with reduced (almost negligible) net magnetic moment per 


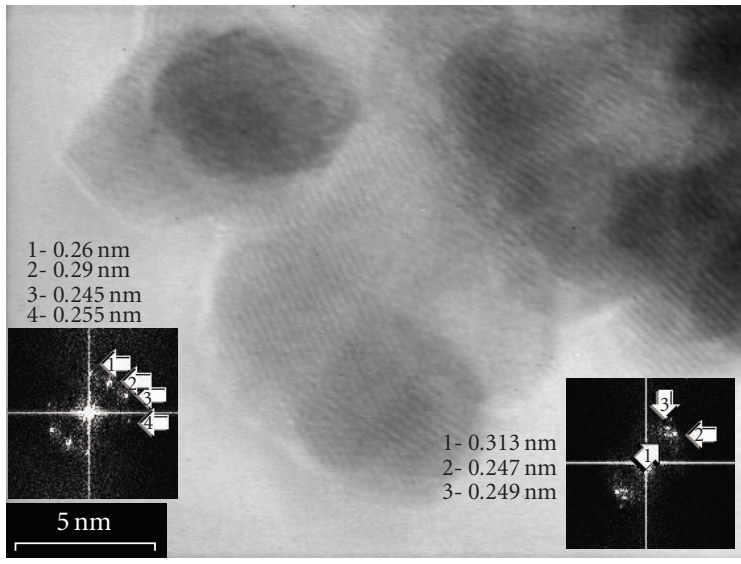

(a)

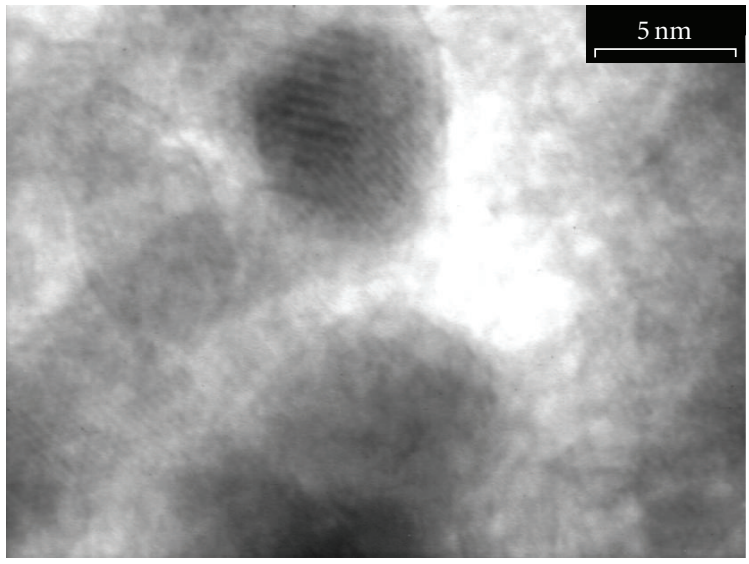

(b)

FIGURE 5: HRTEM images for samples: (a) 01 and (b) 02. Space representations of Fourier transform (displayed as insets on figure) seem to evidence the diffraction planes of maghemite/magnetite.

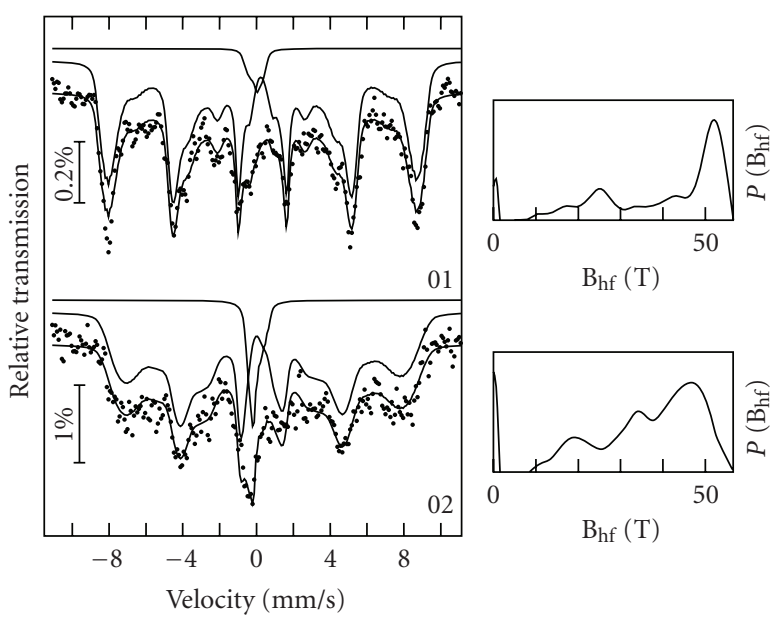

FIGURE 6: Mössbauer spectra (at $80 \mathrm{~K}$ ) of the two as-synthesized nanopowder samples; at the right side, the probability distributions of the hyperfine field are also displayed.

particle seems to be present, affecting/reducing drastically the magnetic dipolar interactions, even in the powder form. The best magnetic performances (a maximum amount of magnetic nanoparticles at room temperature and related highest magnetization) correspond to the ferrofluid obtained by dispersing the well-formed maghemite-based nanoparticles synthesized under a laser power of $55 \mathrm{~W}$.

The reduced magnetization curves of the as-synthesized nanopowders are presented in Figure 7. It is worth mentioning that none of the samples is saturated at the maximum available field of 1.1 T. This behavior can be considered an additional evidence for the disordered spin configuration, connected with the defected structure inside nanoparticles, in agreement with the Mössbauer data. Therefore, the reduced magnetization curves for the two samples were obtained with respect to the specific magnetization at the maximum field (denoted as $M_{s}$ ). The magnetization $M_{s}$ of

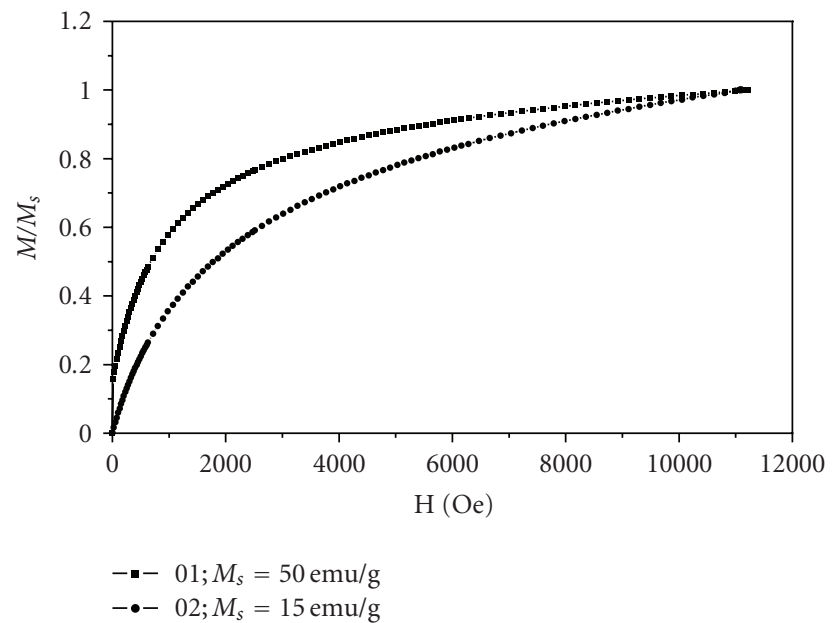

FIgURE 7: Reduced magnetization curves for 01 and 02 nanopowders.

the 01 sample, $50 \mathrm{emu} / \mathrm{g}$, is much greater than for sample $02(15 \mathrm{emu} / \mathrm{g})$ supporting a three times larger magnetic moment per particle in sample 01 as compared with sample 02 in the assumption that the particle mean sizes of the two samples are almost similar. On the other hand, the reduced magnetization of sample 01 at very low field is clearly larger than that of sample 02, providing evidence for a larger amount of magnetic state at room temperature in this sample in agreement with the larger blocking temperature evidenced by Mössbauer spectroscopy.

Following the procedures described in a previous section, the iron oxide nanopowders were subsequently synthesized as water-based magnetic fluids (MFs). TEM analysis of the ferrofluids showed that depending on the nanopowder synthesis parameters, different degrees of agglomeration are still present. The morphology of samples MF01 and MF02 may be examined in Figures 8(a) and 8(b). The 


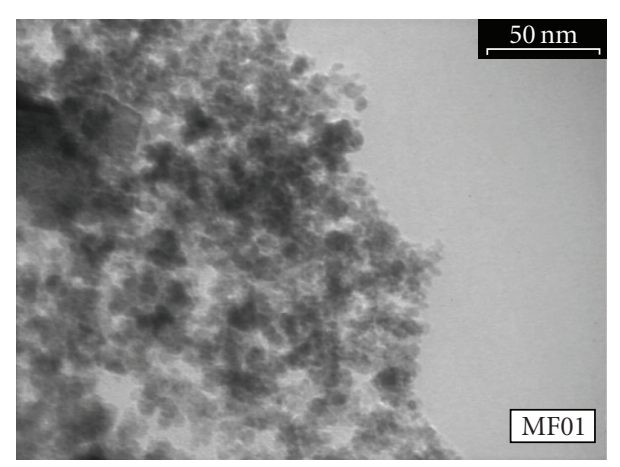

(a)

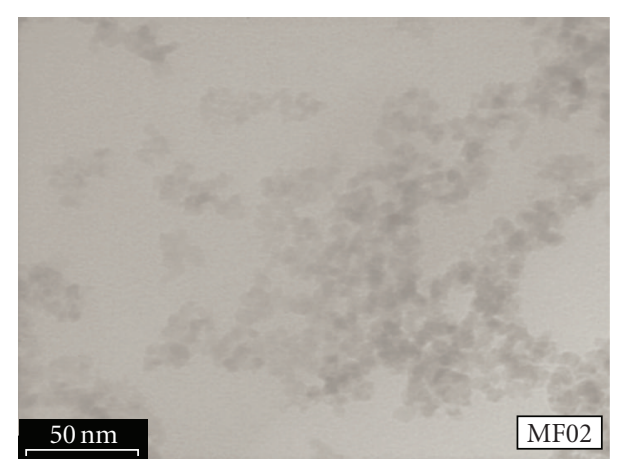

(b)

FIGURE 8: TEM images showing the morphology of the magnetic nanofluids prepared from samples MF01 and MF02, respectively.

nanoparticles exhibit a spherical shape, confirmed by the 0.86 value of the form factor. From SAED analysis (no presented here), an iron oxide cubic structure is deduced, with lattice constants of $0.835 \mathrm{~nm}$ and $0.837 \mathrm{~nm}$ for MF01 and MF02, respectively. This estimation may indicate that the maghemite-like structure is favored in the ferrofluid-derived from the sample synthesized at high laser power. On the other hand, one may observe that the MF prepared from 02 nanoparticles (Figure 8(b)) presents a slightly lower degree of agglomeration as compared with MF02 (Figure 8(a)). The suppression of interparticle interaction in sample MF01 could be less effective, in spite of the fact that insignificant magnetic relaxation differences separate the MF samples.

The reduced magnetization curves of the ferrofluid samples MF01 and MF02, synthesized from the powders 01 and 02, respectively, are shown in Figure 9. The dependencies of the reduced magnetizations versus the applied magnetic field are quite similar to the ones of the powder samples. A major difference concerns the values of the magnetization, $M_{s}$, at the maximum field of $1.1 \mathrm{~T}$. This time these are expressed in $\mathrm{emu} / \mathrm{cm}^{3}$ (or $\mathrm{A} / \mathrm{m}$ ) in order to take into account the inhomogeneous character of the ferrofluid, seen as a liquid-solid composite $\left(M_{s}\right.$ given in emu $/ \mathrm{cm}^{3}$ derives from the specific magnetization in emu/g times the ferrofluid density, in $\mathrm{g} / \mathrm{cm}^{3}$ ). The $M_{s}$ value in sample MF01 is almost 7 times larger than the value in sample MF02, proving clearly the better magnetic performances of the ferrofluid derived from the 01 powder sample. In addition, one observes that the low field part of the reduced magnetization in the magnetic fluid sample MF01 is lower than for the 01 sample and that a certain amount of suparparamagnetic phase is to be found in this sample even at 1.1 T. Therefore, due to the cancellation of interparticle interactions, the magnetometry data infer that the magnetic relaxation at room temperature has to be more advanced in the MF01 ferrofluid sample as compared with the 01 powder sample (in agreement with the Mossbauer data showing a lower blocking temperature in the ferrofluid). Hence, the magnetic relaxation may hide the information about the static spin disorder. The specific magnetizations are not strictly related to the different degree of spin disorder in the samples but, at least qualitatively, the magnetometry results, in agreement with the Mossbauer

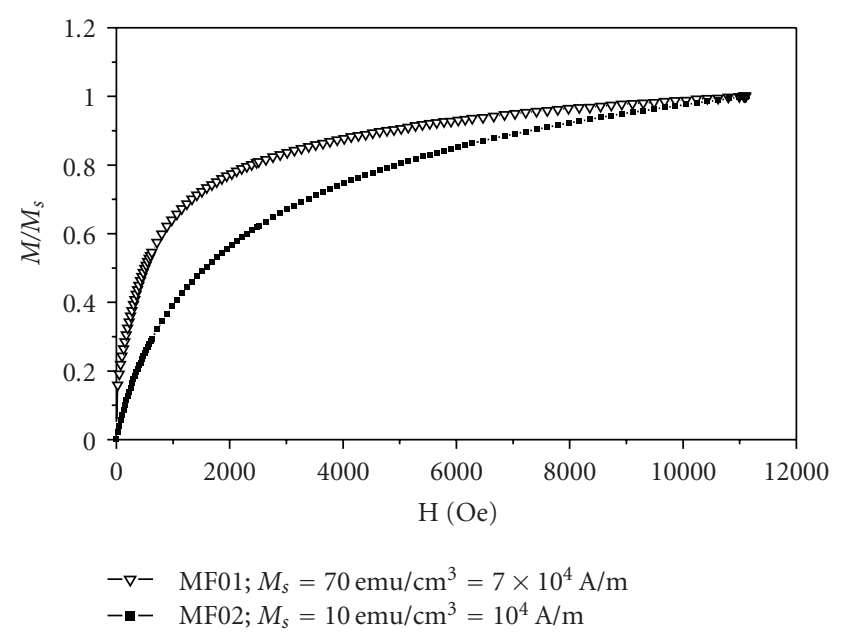

FIGURE 9: Reduced magnetization curves of water magnetic fluid samples prepared from 01 and 02 nanopowders.

ones, support very well the conclusion that the lowest spin disorder is present in the 01 sample and in the corresponding MF01 ferrofluid.

\subsection{Titania, with major $\mathrm{TiO}_{2}$ anatase phase}

\subsubsection{Particle preparation and characterization}

The synthesis of $\mathrm{TiO}_{2}$ nanopowder was performed by employing a modified version of the pyrolysis setup [24] in which $\mathrm{TiCl}_{4}$ and air, as gas-phase precursors, are simultaneously allowed to emerge into the flow reactor (see also Figure 1). Ethylene served as a carrier for the $\mathrm{TiCl}_{4}$ vapors and as an energy transfer agent. A special irradiation geometry employing a central triple nozzle system was used. The focused IR radiation ( $400 \mathrm{~W}$ nominal power) was intersecting at right angles the reactant flows. During all experiments, the total pressure in the reactor was held at 550 mbar.

The samples (labeled $\mathrm{S}_{\mathrm{N}}, \mathrm{S}_{\mathrm{A}}$, and $\mathrm{S} 0$ ) are studied relatively to the input variation of their oxygen precursors. Sample $S_{N}$ was obtained by replacing air with nitrous oxide. A much 
TABLE 2: Synthesis parameters and crystallographic parameters of nano $\mathrm{TiO}_{2}$ particles.

\begin{tabular}{|c|c|c|c|c|c|c|c|c|c|c|}
\hline \multirow{3}{*}{ Sample } & \multirow{3}{*}{$\begin{array}{l}\Phi_{\text {air }}{ }^{*} \\
{[\mathrm{sccm}]}\end{array}$} & \multirow{3}{*}{$\begin{array}{l}\Phi_{\mathrm{C}_{2} \mathrm{H}_{4}}{ }^{*} \\
\left(\mathrm{TiCl}_{4}\right) \\
{[\mathrm{sccm}]}\end{array}$} & \multicolumn{2}{|c|}{$\mathrm{TiO}_{2}$-phase proportion** } & \multicolumn{4}{|c|}{ Lattice parameters** } & \multicolumn{2}{|c|}{$D$ Mean crystallite dimension $[\mathrm{nm}]$} \\
\hline & & & \multirow[t]{2}{*}{ A $(\%)$} & \multirow[t]{2}{*}{$\mathrm{R}(\%)$} & \multicolumn{2}{|c|}{$\begin{array}{c}\text { A (JCPDS 21-1272) } \\
\begin{array}{c}a=3.785 \AA \\
c=9.513 \AA\end{array}\end{array}$} & \multicolumn{2}{|c|}{$\begin{array}{c}\mathrm{R}(\mathrm{JCPDS} 21-1272) \\
\begin{array}{c}a=4.593 \AA \\
c=2.959 \AA\end{array}\end{array}$} & \multirow[t]{2}{*}{ A } & \multirow[t]{2}{*}{$\mathrm{R}$} \\
\hline & & & & & $a(\AA)$ & $c(\AA)$ & $a(\AA)$ & $c(\AA)$ & & \\
\hline $\mathrm{S}_{\mathrm{N}}$ & $\begin{array}{l}10 \\
\left(\mathrm{~N}_{2} \mathrm{O}\right)\end{array}$ & 100 & 64.1 & 35.9 & 3.805 & 9.56 & 4.70 & 2.92 & 14.4 & 4.2 \\
\hline$S_{\mathrm{A}}$ & 50 & 100 & 74.6 & 25.4 & 3.81 & 9.57 & 4.64 & 2.965 & 17.8 & 15.0 \\
\hline So & 150 & 100 & 92.3 & 7.7 & 3.81 & 9.55 & 4.63 & 2.95 & 18.9 & 21.4 \\
\hline
\end{tabular}

${ }^{*} \Phi_{\mathrm{C}_{2} \mathrm{H}_{4}}$ and $\Phi_{\text {air }}$, are the flows of the ethylene (carrier of $\mathrm{Fe}(\mathrm{CO})_{5}$ vapors) and of the air oxidizer, respectively (in standard cubic centimeter per minute); ${ }^{* *} \mathrm{~A}$ and $\mathrm{R}$ stand for anatase and rutile, respectively; $a$ and $c$ are the values of the lattice parameters of titania, according to standard JCPDS 21-1272 data.

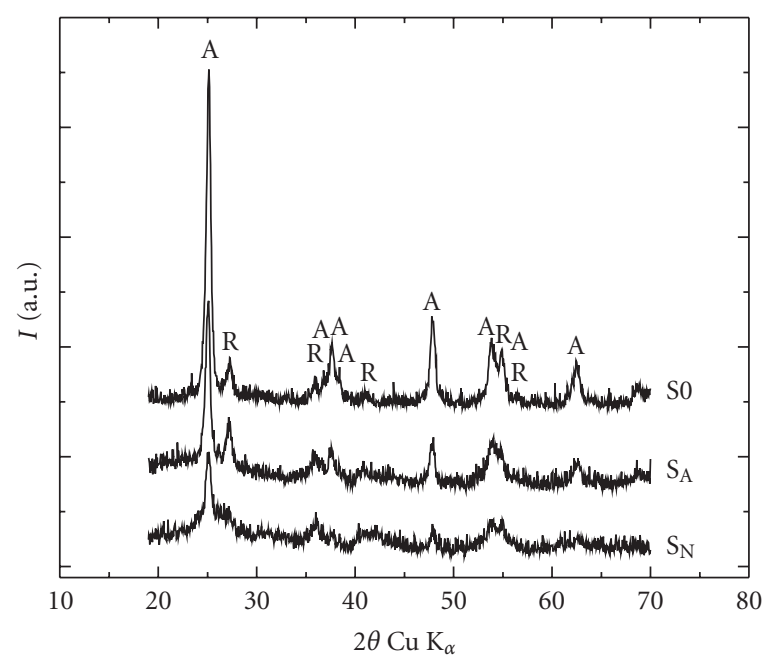

FIGURE 10: XRD diffraction patterns for the nanotitania samples $S_{N}$, $\mathrm{S}_{\mathrm{A}}$, and $\mathrm{S} 0$, with anatase $(\mathrm{A})$ and rutile $(\mathrm{R})$ peak identification.

lower air flow was used to obtain sample $\mathrm{S}_{\mathrm{A}}$ as compared to sample S0. The main experimental parameters are listed in Table 2. In the last columns of the table are gathered the mean crystallite sizes [25] as well as the lattice parameters $(a, c)$ as extracted from the XRD patterns (see below).

The obtained titanium oxide nanostructures were characterized by XRD, TEM, and SAED.

XRD phase analysis (Figure 10 and the last columns of Table 2) reveals an overwhelming dominancy of the anatase phase (more than about 92\%) in the sample S0, obtained at the highest air precursor concentration. It was already observed [26] that for titania produced by RF thermal plasma, rutile formation is favored by oxygen-deficient gasphase $\mathrm{TiO}_{2}$ clusters while anatase tends to condense from oxygen-rich clusters. We should mention that for both air and nitrous oxide, at lower air flows (e.g., $10 \mathrm{sccm}$ for sample $\mathrm{S}_{\mathrm{N}}$ ), the powder was gray with slight blue parts. At high air input flows ( $150 \mathrm{sccm}$ for sample S0), the color of the powder becomes light yellow to white. Some salient features characterize the $S_{N}, S_{A}$, and S0 series: (i) the significant decrease of the mean particle sizes for $S_{N}$ and $S_{A}$ relatively

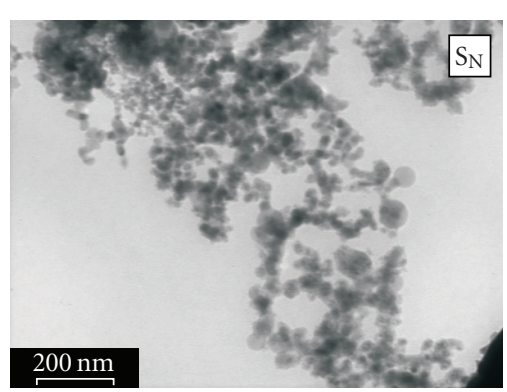

(a)

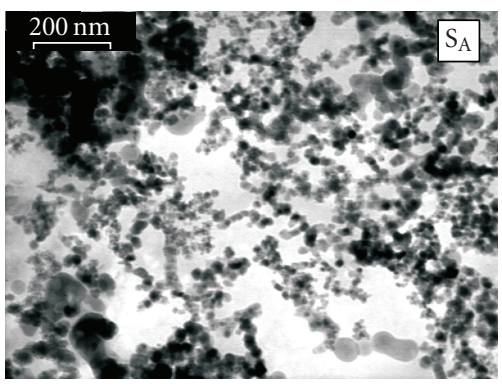

(b)

Figure 11: General TEM view of the samples $\mathrm{S}_{\mathrm{N}}(\mathrm{a})$ and $\mathrm{S}_{\mathrm{A}}(\mathrm{b})$.

to S0, particularly concerning the rutile phase; and (ii) the decrease of the total amount of the $\mathrm{TiO}_{2}$ phases relatively to the S0 sample, especially in case of the anatase phase. For the $\mathrm{TiO}_{2} \mathrm{~S}_{\mathrm{A}}$ sample, anatase percentage is approximately $74 \%$, which is quite close to the well-known Degussa P25 commercial sample.

Low-magnification TEM micrographsfor $\mathrm{TiO}_{2}$ samples $\mathrm{S}_{\mathrm{N}}$ and $\mathrm{S}_{\mathrm{A}}$ (Figure 11) show groups of loosely-bound aggregated nanoparticles.

The SAED patterns for samples $\mathrm{S}_{\mathrm{A}}$ and $\mathrm{S} 0$ are presented in Figure 12. The identification of the interplanar distances is indicated by arrows and these qualitative results can be directly compared with those obtained by means of XRD. In general, SAED analysis confirms that the titania nanoparticles are a mixture of anatase and rutile. However, 


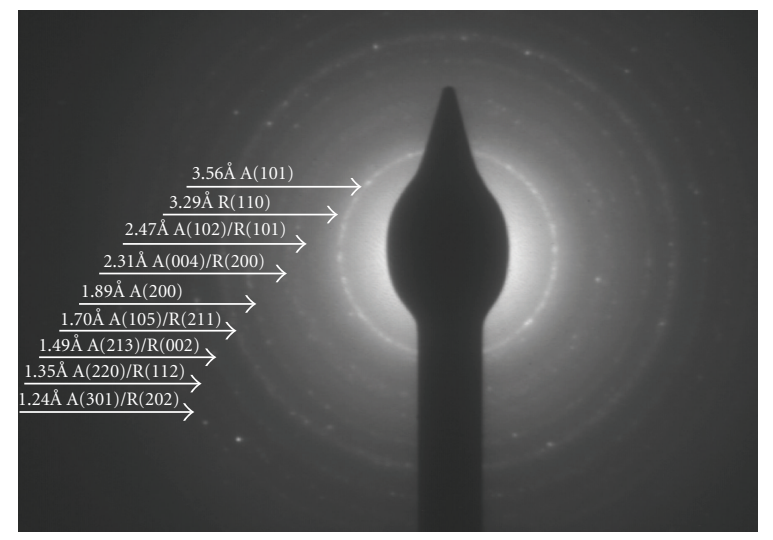

(a)

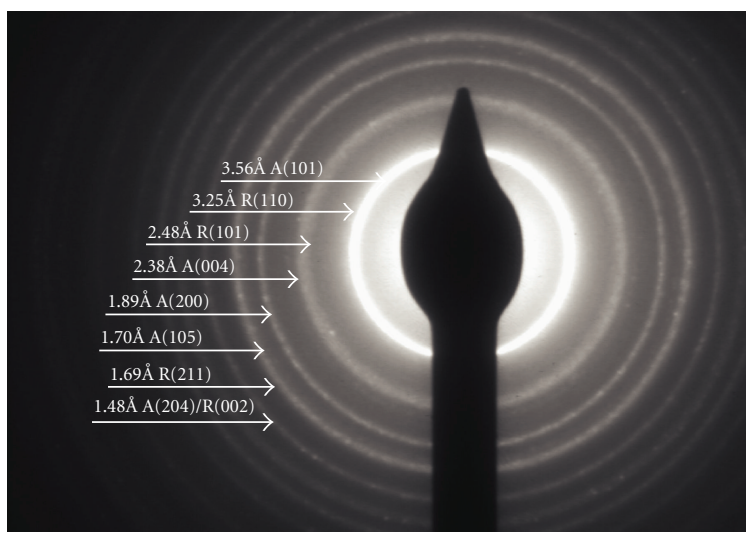

(b)

Figure 12: SAED patterns for samples $S_{A}$ and S0.

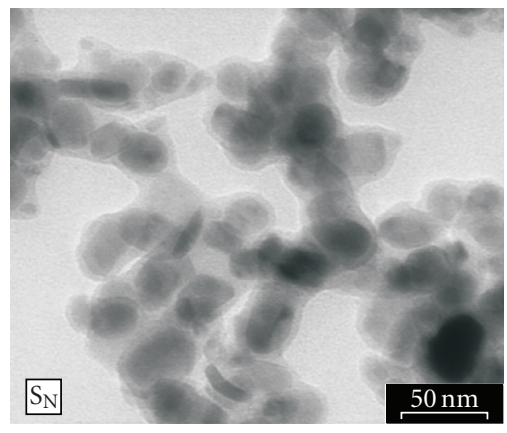

(a)

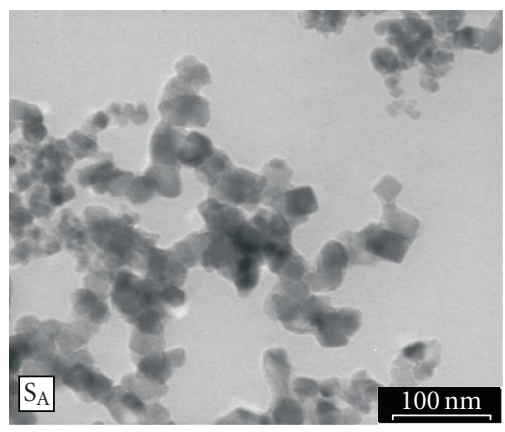

(c)

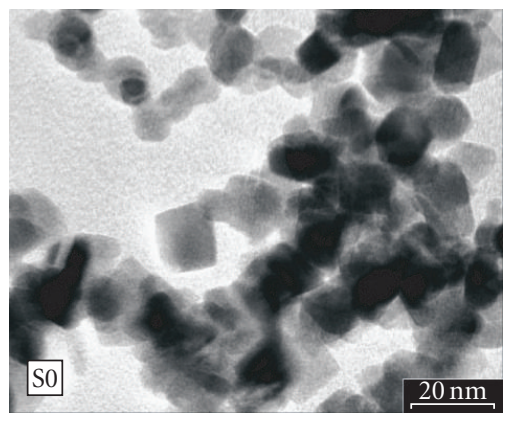

(e)

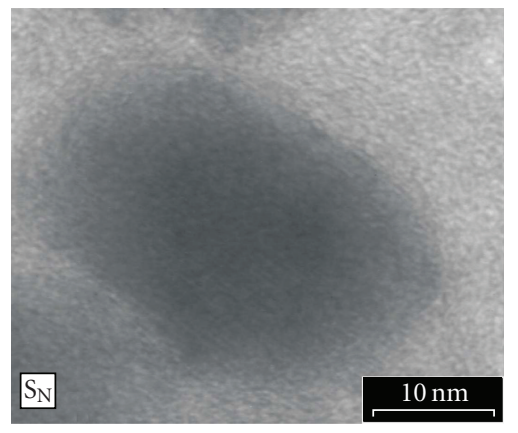

(b)

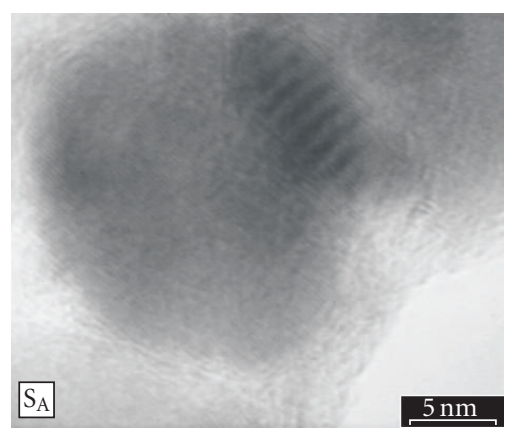

(d)

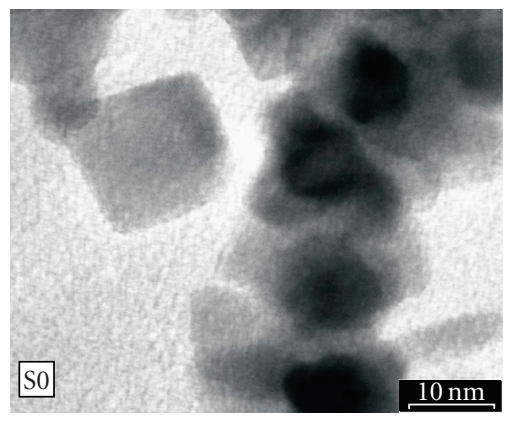

(f)

FIgURE 13: Comparative TEM analysis for medium- (a, c, and e) and high-resolution (b, $d$, and f) images of titania samples, showing the different morphologies of $\mathrm{S}_{\mathrm{N}}, \mathrm{S}_{\mathrm{A}}$, and $\mathrm{S} 0$. 
increased crystallinity and dominant anatase phase are found for the reference sample (S0). We should note that the diffusivity observed in the SAED pattern of sample $\mathrm{S}_{\mathrm{A}}$ could be due not only to an amorphous material but also to the increased number of crystalline nanometer-sized particles [27]. The most intense diffraction rings can be assigned to the (101) anatase (at $3.52 \AA$ ) and (110) rutile (at $3.25 \AA$ ). Some rings may appear by a superposition of anatase and rutile reflections, such as the rings at $2.48 \AA$ and $1.68 \AA$. In case of the better crystallinity of sample S0, the complementary ring at $1.4 \AA$ (corresponding to rutile (007) and anatase (204)) is identified.

In Figure 13, a comparative TEM analysis for medium(a, c, and e) and high-resolution (b, d, and f) images of $S_{N}, S_{A}$ and $S 0$ titania samples is performed. At a higher magnification, the TEM micrographs of samples discussed in this work exhibit both round-shaped and elongated or facetted particles with irregular shapes and sizes (Figures 13(a)-13(f)). Primary nanocrystals seem to be often present. In Figure 13(b), an isolated $S_{N}$ primary nanocrystal is presented, showing an elongated (about $15 \mathrm{~nm}$ ) shape. Particles surrounded by an amorphous layer (Figures 13(a) and 13(c)) appear in sample $S_{N}$ and $S_{A}$, respectively. The rather well-defined microcrystallites of sample S0 exhibit irregular, mostly polyhedral shapes (Figure 13(f)).

\section{CONCLUSIONS}

Recent results obtained in the preparation of gamma iron oxide $\left(\gamma-\mathrm{Fe}_{2} \mathrm{O}_{3}\right)$ and titania $\left(\mathrm{TiO}_{2}\right)$ semiconductor nanostructures using the laser pyrolysis method are outlined. The properties of different nanometric iron oxides prepared by laser pyrolysis were analyzed from the point of view of their morphology and magnetic behavior. The nanoparticles are characterized by a cubic maghemite/magnetite structure. Maghemite phase seems to prevail in the nanopowders obtained at the highest laser power. These nanoparticles also present a better crystallinity and slightly larger mean crystallite dimensions. The analysis of samples as waterbased nanofluids shows that the best magnetic performances (a maximum amount of magnetic nanoparticles at room temperature and related highest magnetization) correspond to the ferrofluid derived from maghemite-based nanoparticles synthesized under a higher laser power.

$\mathrm{TiO}_{2}$ nanoparticles comprising a mixture of anatase and rutile phases were synthesized via the sensitized laser pyrolysis of $\mathrm{TiCl}_{4}$ - (vapors) based gas-phase mixtures. $\mathrm{TiO}_{2}$ samples were obtained by varying the amount of oxidizing agent (air). Enhanced crystallinity and larger crystallite mean sizes are observed at increased amount of the oxidizing agent. Samples with a major concentration of anatase phase (about $90 \%$ ) were obtained by the same technique by using as precursors very high air flows.

\section{ACKNOWLEDGMENT}

This work was supported by the Romanian Education Ministry through CEEX (Project no. S2/C8/2005), PNCD2
(71/083/2007), and NUCLEU: LAPLACE 2 (PN 06 36/2008) programs.

\section{REFERENCES}

[1] M. R. Hoffmann, S. T. Martin, W. Choi, and D. W. Bahnemann, "Environmental applications of semiconductor photocatalysis," Chemical Reviews, vol. 95, no. 1, pp. 69-96, 1995.

[2] M. A. Fox and M. T. Dulay, "Heterogeneous photocatalysis," Chemical Reviews, vol. 93, no. 1, pp. 341-357, 1993.

[3] K. Pirkanniemi and M. Sillanpää, "Heterogeneous water phase catalysis as an environmental application: a review," Chemosphere, vol. 48, no. 10, pp. 1047-1060, 2002.

[4] Y. Matsumoto, "Energy positions of oxide semiconductors and photocatalysis with iron complex oxides," Journal of Solid State Chemistry, vol. 126, no. 2, pp. 227-234, 1996.

[5] D. G. Shchukin, E. A. Ustinovich, D. V. Sviridov, and A. I. Kulak, "Titanium and iron oxide-based magnetic photocatalysts for oxidation of organic compounds and sulfur dioxide," High Energy Chemistry, vol. 38, no. 3, pp. 167-173, 2004.

[6] L. Palmisano, M. Schiavello, A. Sclafani, C. Martin, I. Martin, and V. Rives, "Surface properties of iron-titania photocatalysts employed for 4-nitrophenol photodegradation in aqueous $\mathrm{TiO}_{2}$ dispersion," Catalysis Letters, vol. 24, no. 3-4, pp. 303315, 1994.

[7] B. O’Regan and M. Gràtzel, "A low-cost, high-efficiency solar cell based on dye-sensitized colloidal $\mathrm{TiO}_{2}$ films," Nature, vol. 353, pp. 737-740, 1991.

[8] X. H. Wang, J.-G. Li, H. Kamiyama, and T. Ishigaki, "Fe-doped $\mathrm{TiO}_{2}$ nanopowders by oxidative pyrolysis of organometallic precursors in induction thermal plasma: synthesis and structural characterization," Thin Solid Films, vol. 506-507, pp. 278-282, 2006.

[9] M. T. Swihart, "Vapor-phase synthesis of nanoparticles," Current Opinion in Colloid \& Interface Science, vol. 8, no. 12, pp. 127-133, 2003.

[10] I. Morjan, R. Alexandrescu, I. Soare, et al., "Nanoscale powders of different iron oxide phases prepared by continous laser irradiation of iron pentacarbonyl-containing gas precursors," Materials Science and Engineering C, vol. 23, no. 1-2, pp. 211216, 2003.

[11] R. Alexandrescu, I. Morjan, M. Scarisoreanu, et al., "Structural investigations on $\mathrm{TiO}_{2}$ and $\mathrm{Fe}$-doped $\mathrm{TiO}_{2}$ nanoparticles synthesized by laser pyrolysis," Thin Solid Films, vol. 515, no. 24, pp. 8438-8445, 2007.

[12] S. Veintemillas-Verdaguer, M. Del Puerto Morales, O. BomatiMiguel, et al., "Colloidal dispersions of maghemite nanoparticles produced by laser pyrolysis with application as NMR contrast agents," Journal of Physics D, vol. 37, no. 15, pp. 20542059, 2004.

[13] H. Maskrot, Y. Leconte, N. Herlin-Boime, et al., "Synthesis of nanostructured catalysts by laser pyrolysis," Catalysis Today, vol. 116, no. 1, pp. 6-11, 2006.

[14] F. Lacour, O. Guillois, X. Portier, H. Perez, N. Herlin, and C. Reynaud, "Laser pyrolysis synthesis and characterization of luminescent silicon nanocrystals," Physica E, vol. 38, no. 1-2, pp. 11-15, 2007.

[15] C. Jäger, F. Huisken, H. Mutschke, Th. Henning, W. Poppitz, and I. Voicu, "Identification and spectral properties of PAHs in carbonaceous material produced by laser pyrolysis," Carbon, vol. 45, no. 15, pp. 2981-2994, 2007. 
[16] A. Tomescu, R. Alexandrescu, I. Morjan, et al., "Structural and sensing properties of a novel $\mathrm{Fe} / \mathrm{Fe}_{2} \mathrm{O}_{3}$ /polyoxocarbosilane core shell nanocomposite powder prepared by laser pyrolysis," Journal of Materials Science, vol. 42, no. 5, pp. 1838-1846, 2007.

[17] R. Alexandrescu, I. Morjan, I. Voicu, et al., "Combining resonant/non-resonant processes: nano-meter-scale ironbased material preparation via the $\mathrm{CO}_{2}$ laser pyrolysis," Applied Surface Science, vol. 248, no. 1-4, pp. 138-146, 2005.

[18] G. W. Flynn, C. S. Parmenter, and A. M. Wodtke, "Vibrational energy transfer," Journal of Physical Chemistry, vol. 100, no. 31, pp. 12817-12838, 1996.

[19] R. Alexandrescu, "Laser-stimulated processes in metal carbonyls for metal-based film synthesis," Applied Surface Science, vol. 106, pp. 28-37, 1996.

[20] G. Herzberg, Molecular Spectra and Molecular Structure: Infrared and Raman Spectra of Polyatomic Molecules, vol. 2, Van Nostrand Reinhold, New York, NY, USA, 1945.

[21] K. Elihn, F. Otten, M. Boman, et al., "Size distributions and synthesis of nanoparticles by photolytic dissociation of ferrocene," Applied Physics A, vol. 72, no. 1, pp. 29-34, 2001.

[22] D. Bica, L. Vékás, M. V. Avdeev, et al., "Sterically stabilized water based magnetic fluids: synthesis, structure and properties," Journal of Magnetism and Magnetic Materials, vol. 311, no. 1, pp. 17-21, 2007.

[23] V. Kuncser, G. Schinteie, B. Sahoo, et al., "Magnetic interactions in water based ferrofluids studied by Mössbauer spectroscopy," Journal of Physics: Condensed Matter, vol. 19, no. 1, Article ID 016205, 16 pages, 2007.

[24] R. Alexandrescu, F. Dumitrache, I. Morjan, et al., " $\mathrm{TiO}_{2}$ nanosized powders by $\mathrm{TiCl}_{4}$ laser pyrolysis," Nanotechnology, vol. 15 , no. 5, pp. 537-545, 2004.

[25] R. A. Spurr and H. Myers, "Quantitative analysis of anataserutile mixtures with an X-ray diffractiometer," Analytical Chemistry, vol. 29, no. 5, pp. 760-762, 1957.

[26] J.-G. Li, H. Kamiyama, X.-H. Wang, Y. Moriyoshi, and T. Ishigaki, " $\mathrm{TiO}_{2}$ nanopowders via radio-frequency thermal plasma oxidation of organic liquid precursors: synthesis and characterization," Journal of the European Ceramic Society, vol. 26, no. 4-5, pp. 423-428, 2006.

[27] J. Arbiol, J. Cerdà, G. Dezanneau, et al., "Effects of Nb doping on the $\mathrm{TiO}_{2}$ anatase-to-rutile phase transition," Journal of Applied Physics, vol. 92, no. 2, pp. 853-861, 2002. 


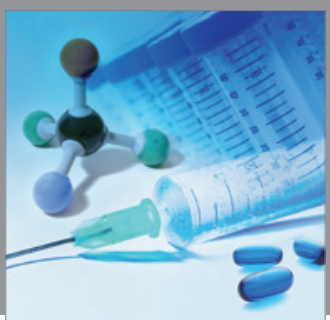

International Journal of

Medicinal Chemistry

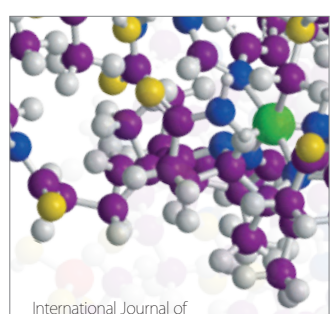

Carbohydrate Chemistry

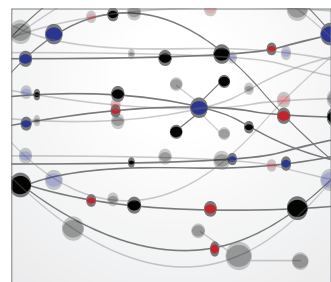

The Scientific World Journal
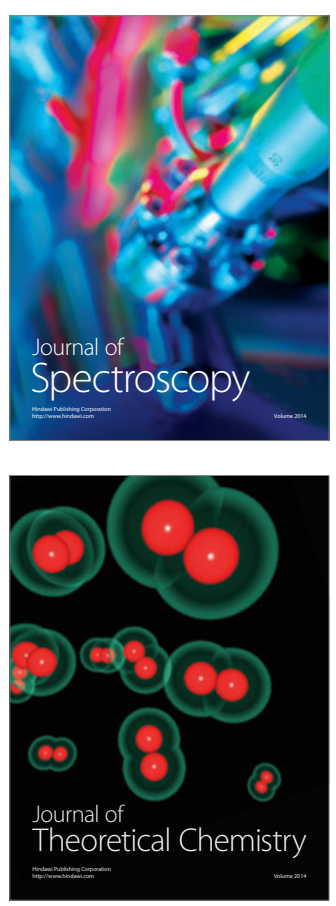
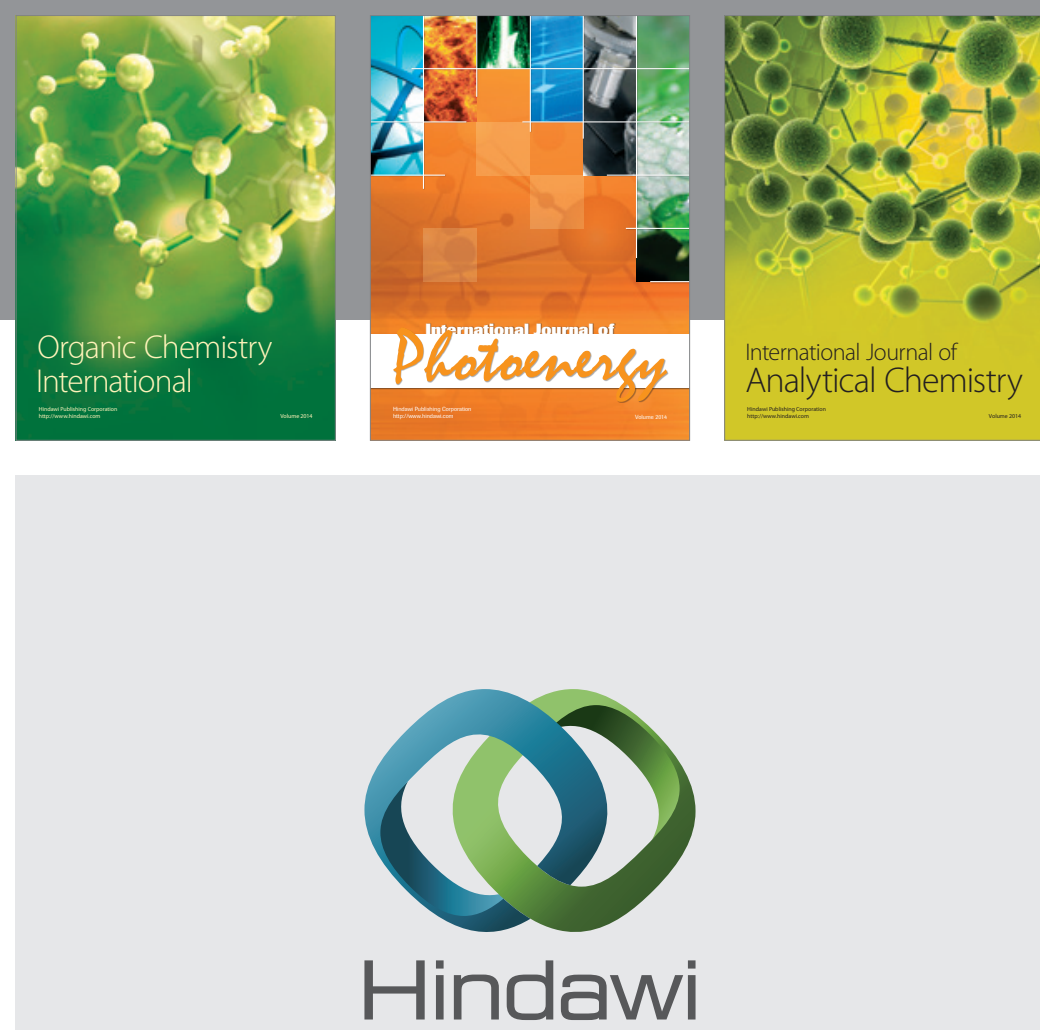

Submit your manuscripts at

http://www.hindawi.com
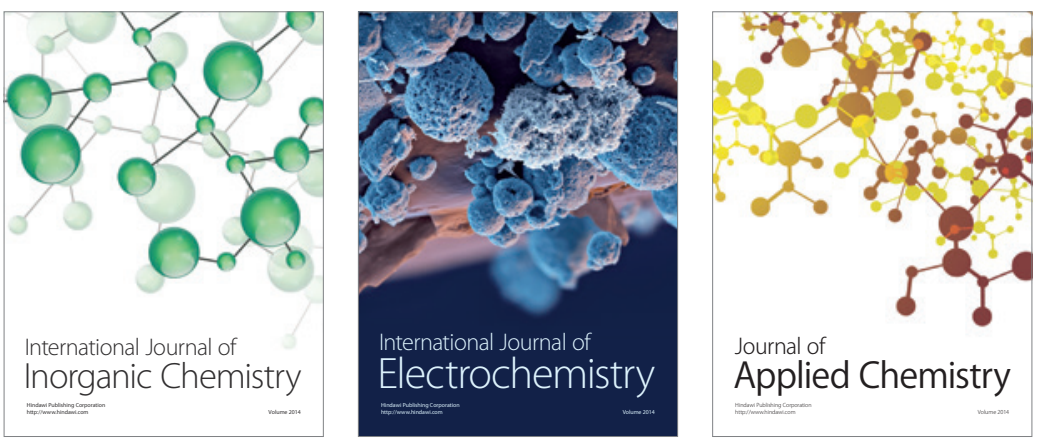

Journal of

Applied Chemistry
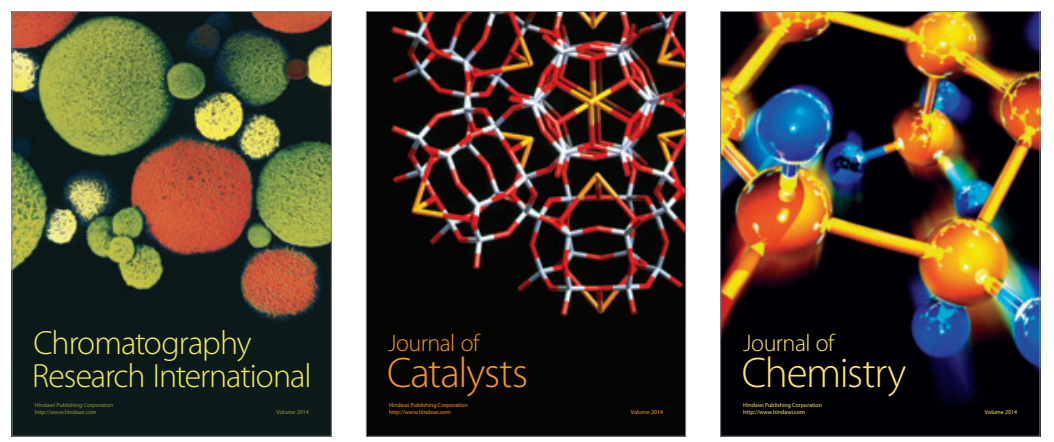
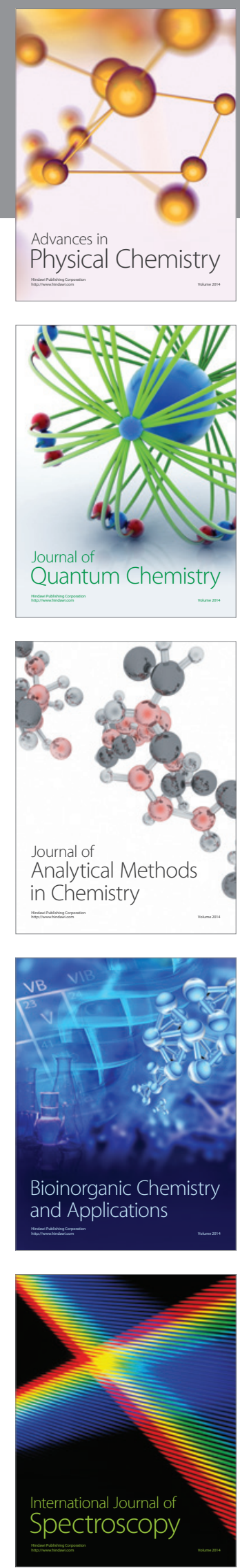